\title{
Modes of Theory Integration
}

\author{
Dirk S. Hovorka \\ University of Sydney \\ Sydney, AU \\ dirk.hovorka@sydney.edu.au
}

\author{
Kai Larsen \\ University of Colorado \\ Boulder, $\mathrm{CO}$ \\ kai.larsen@colorado.edu
}

\section{Introduction}

Multiple social science fields, including Information Systems (IS), share a desire to make sense of the how humans, technology and information can be organized to support desired modes of behavior. Over the past three decades IS has tended to import reference theories. More recently there has been increased effort to obtain legitimacy by creating 'native' IS theories. While some decry the obsession with theory [1] publication outlets continue to emphasize the primacy of theory development and testing as the maximal contribution to the field [2]. As a result of this emphasis on theory, IS has moved from having a relative paucity of theories about phenomena of interest, to its current state of multiple, overlapping, and overly narrow theories. IS, along with many reference disciplines, are now faced with a problem common to social sciences-how to make sense of a disparate range of theories originating across multiple fields researching the same phenomenon.

In this paper we focus on one approach, theory integration, as a means of understanding the breadth and range of theories used in IS. Theoretical coherence in a field presents multiple challenges, from construct renaming and the addition/deletion of constructs in the pursuit of publishable 'novel' theories, to differences in conceptualization, nomenclature, structure and etiology of 'schools of thought' across disciplinary boundaries [3, 4]. While theory integration, the connection of theories and processes into more internally coherent models should serve to progress IS theoretical knowledge, principles and guidelines for such consilience is missing. In addition, it is critical to establish external correspondence to observable events and processes. Consilience, or the convergence of knowledge by the linking of facts and fact-based theory across disciplines to create a common groundwork of explanation" [5 p. 8], may support the development of such principles and guidelines.

In this research we offer a framework for integration that can guide efforts to reduce our sense of being "theory weary" [6] and increase both coherence and correspondence of theories. We illustrate three modes of theory integration: Construct Integration, Domain Integration, and Inter-field Integration. For the purpose of clarity and consistency of terms we utilize Weber's [7] framework for theory development and evaluation.

\section{Theory articulation: a vocabulary}

The stated goal of Weber's framework is "to articulate the nature of and characteristics of high-quality theory" [7, p. 2]. The foundation of Weber's framework rests on "its reliance on a theory of ontology to provide more formal and precise foundations for the evaluation of theory" (p. 2). The framework distinguishes between a theory's parts and the characteristic of the whole, providing a point of entry for approaches to theory development and integration both within and across disciplines. Weber's framework makes visible the tension between two competing concepts: theory coherence and theory correspondence that can be productively applied in theory integration.

One implication of Weber's framework comes from emphasis on theory coherence [8] for evaluation of theory. Coherence describes the structural conditions which justify belief in a theory and requires that theory elements maintain consistency with other elements and avoid ambiguity [9]. Weber's framework is specific in articulating the necessary and sufficient conditions for precise description or 
propositions of a theory's 'parts', allowing for detailed evaluation of theory coherence. Here it is valuable to make a distinction between coherence among the elements within a theory and coherence of theory elements with related theory, both disciplinary and transdisciplinary. We refer to these as internal and external coherence respectively.

\subsection{Internal Coherence.}

Discussing internal coherence requires examination of recent work related to construct correspondence and independence [10] which suggested that the correspondence (synonymy) and independence (polysemy) of constructs may be measured through examination of the language in questionnaire items. This approach is applicable in that it enables detection of correspondent constructs, which are critical for theory integration.

As an example we consider constructs in the Technology Acceptance Model (TAM; [11]). Because the most popular version of TAM contained the key constructs ease of use, usefulness, and intention to use, most papers that work to extend the theory will retain these three constructs, presenting them using the same names. We estimate that thousands of extension papers have been published, most of which do not build upon or cite each other. This means that while the core concepts remain the same, each paper will add other constructs, and these constructs do not retain a consistent set of names. For example, many different names are used in these extension papers to refer to the construct social influence, which soon became a staple of these extension models. While highimpact constructs like social influence [12], social norm [13], and social factors [14] may be well known to many, few may be aware of superior's influence [15], social pressure [16], Chau and Hu's (2002) peer influence, colleague opinion [17], or Broan and Venkatesh's [18] normative beliefs: workplace referents' influences. Each of these constructs can be shown to be semantically synonymous and so potentially substitutable [19]. This suggests that even within theories, we've lost the ability to identify what has already been done and have forfeited the ability to take full advantage of cumulative studies. However, because the language of the construct measurement items remain fairly constant, it is possible to use semantic algorithms to re-integrate the constructs and overall theory [19]. Because of the core of shared constructs, integration of the nomological network for one theory is likely to be especially fruitful ground [20].

\subsection{External Coherence}

In contrast, traditional empiricism develops theory and evaluates theory quality based on the concept of theory correspondence - the extent to which a theory explains or predicts an empirical phenomenon in the world. Individually and collectively, members of a research community [21] share commitments, a symbolic language, models, instruments, and values [8] which regulate how some slice of reality is encapsulated by constructs, identify the allowable types of associations, and detail the semantic meaning of the definitions of all the criteria proposed by Weber [7]. Theory comparison has long relied on empirical testing to evaluate which theory better accounts for the data. Indeed many empiricists assert that a theory's value is measured by its resistance to refutation and that a theory loses primacy when a new theory exhibits better correspondence to the available data [22]. Evaluation requires comparing two theories to ascertain whether "the original or the proposed alternative is better for whatever it is scientists do" [23, p. 96].

But any new theory of a specified phenomenon exists within the same theory domain - the focal phenomenon remains the same and many of the ancillary phenomenon are relevant. Thus they have correspondence to the same nomological net. A nomological network "includes a theoretical framework representing the theoretical constructs and their relationships, an empirical framework demonstrating the measurements and their relationships, and the linkages between those two frameworks" [24 p.3]. Because of shared classes of constructs across disciplines and a shared focus on established and emerging phenomenon, integration across nomological networks provides opportunities for theory development.

The attributes of coherence and correspondence creates two opportunities. First, we identify a valuable distinction between coherence among the elements within a theory and coherence of theory elements with related theory, both disciplinary and transdisciplinary. Second, there is an opportunity to utilize the functional aspects of what a theory does providing a specific account that corresponds to a phenomenon in the world - to determine and potentially integrate correspondent theory from other fields. We now address each of these 
opportunities in turn and discuss their implications in the practice of research.

\section{Modes of Theory Integration}

Theory Integration is an approach to theory development that builds upon existing knowledge to create more robust theory with broader scope [25, 26]. In general, theory integration involves bringing two theories together to account for phenomenon that neither can address independently [27]. We identify three modes of theory integration that will benefit the IS field. First, at a basic but important level, Construct Integration consolidates synonymous constructs from competing Domain Integration provides theoretical accounts built by integrating different theories which account for the same underlying theory domain. For example UTAUT [12] is described as a 'unified model' of technology acceptance which resulted from the integration of eight existing and nomologically overlapping models. Another Domain Integration approach is the development of multi-level models [28, 29] which provide accounts of a phenomenon across level of analysis. A third mode is Inter-field Integration which draws on concepts, perspectives and relationships from different fields to develop more robust theory. We now describe these three modes of integration and discuss how they can provide guidance in detecting opportunities for theory integration.

\subsection{Mode 1: Construct Integration}

Construct proliferation and overlap has been identified as a potential problem for creating a cumulative research tradition in IS [30]. Many studies which seek to add new constructs to existing models do not adequately review existing literature and either rename or recreate constructs which have been previously tested $[31,32]$. This results in a large number of synonymous constructs. Synonymy between two constructs may be found by measuring the similarity of all their items using Natural Language Processing (NLP) algorithms, and reducing that set of items down to the highestsimilarity items and drawing an average score for these [10]. Figure 1 shows how synonymy between reflective constructs $\mathrm{A}$ and $\mathrm{B}$ are detected because the average similarity between their items are high. The same is also shown to be true for formative items because not all items are compared, but rather the most similar pairs of items.

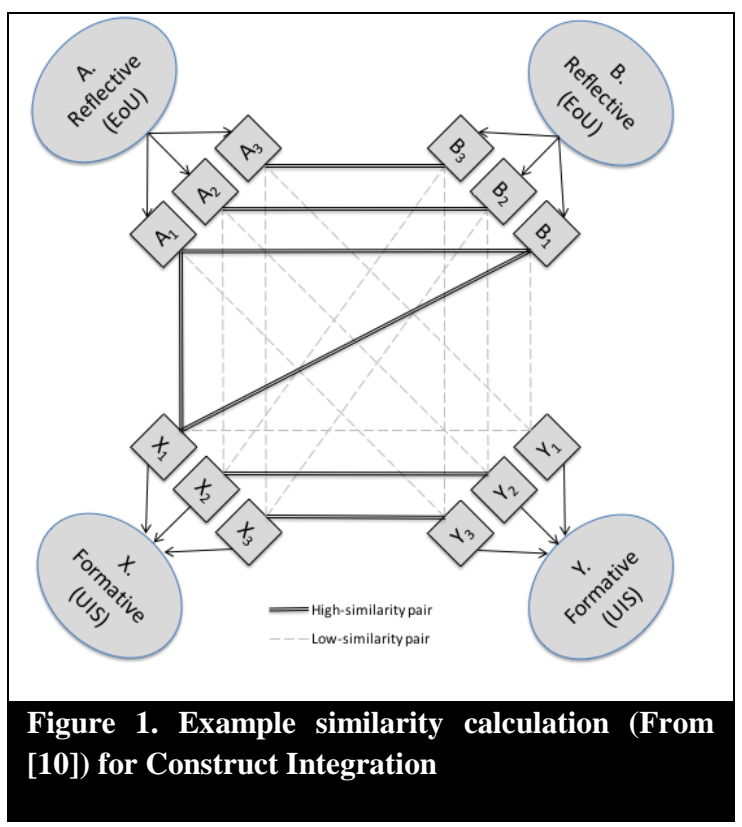

In this example it would be reasonable to propose integration of a theory containing construct A with a theory containing construct B providing they both are in the same theory domain (share a common dependent variable). It is important to note that the resultant integrated theory will still require empirical testing and that the existing statistical associations with other variables may not be sufficient to provide confirmatory evidence. However, if two constructs that are not part of the base of the theory are found and detected to be synonymous, they will both have been tested with the same set of core constructs (ease of use, usefulness, and intention to use in the case of TAM). This means that in the case of articles integrating TAM, a set of at least four synonymous construct pairs may have been detected between two candidates for integration. Therefore, six correlations are available between these constructs from each candidate, and at a minimum, qualitative evaluation may be provided about the extent to which the two may be integrated without collection of additional quantitative evidence. This approach may also be used to detect relationships between formative and reflective constructs, as is done between construct $\mathrm{X}$ and construct $\mathrm{B}$, where the reflective construct ease of use may exist in a part-whole relationship to 
another construct, such as user information satisfaction.

Of course, setting, sample size, and many other context-dependent variables may play into the effect sizes, and should be taken into account when evaluating results from different studies.

\subsection{Mode 2: Domain Integration}

Theoretical coherence is challenged by the proliferation of constructs, models, and theories resulting in "a clutter of partially articulated, partially tested theories in the information systems discipline that leads to 'overload' and 'disarray' “ [7, p. 17]. Weber [7] emphasizes internal coherence among theory parts within the theory domain.. For Weber a theory domain is the subset of phenomena accounted for by the set of focal and ancillary phenomena. This perspective invites new logic for theory integration based on theoretical elements in a larger field of associations, that of the nomological net. In this approach nomologically interrelated sets of propositions are combined to integrate theory [33] within the same domain.

To illustrate this mode we offer a thought experiment in which we select a set of quantitative IS research publications and extract all the constructs and associations between constructs in each paper. Each theory contains a set of constructs representing classes of things connected with associations, which have been empirically derived within each paper and are warranted belief. We can use semantic analysis of the constructs [see for example: 10, 24] to determine where constructs in different studies (within a discipline or even between disciplines) are proxies for the same property of a class of things (e.g., constructs with different names which actually measure the same properties of the same class of thing). At least within identical classes of things we assume transitivity of local models such that associations from distinct studies can be combined by registering each network around in-common constructs as shown in Figure 2.

This allows us to create a nomological net of classes of things, attributes of things and associations by rigorously combining models in the extant literature. For example, in Figure 2, hypothetical Studies I, II and III are revealed to contain constructs-in-common allowing the construction of a theoretical nomological net (IV). Semantic analysis reveals that construct A and construct $\mathrm{Z}$ are synonymous and provide a point of overlap between studies I and II.
Multiple occurrences of the same construct are indicated by the larger circle. The synonymy between constructs $\mathrm{A}$ and $\mathrm{Z}$ also reveals that the $\mathrm{A}(\mathrm{Z})$ to $\mathrm{C}$ relationship has been tested twice as indicated by the thicker $\mathrm{A}-\mathrm{C}$ line.

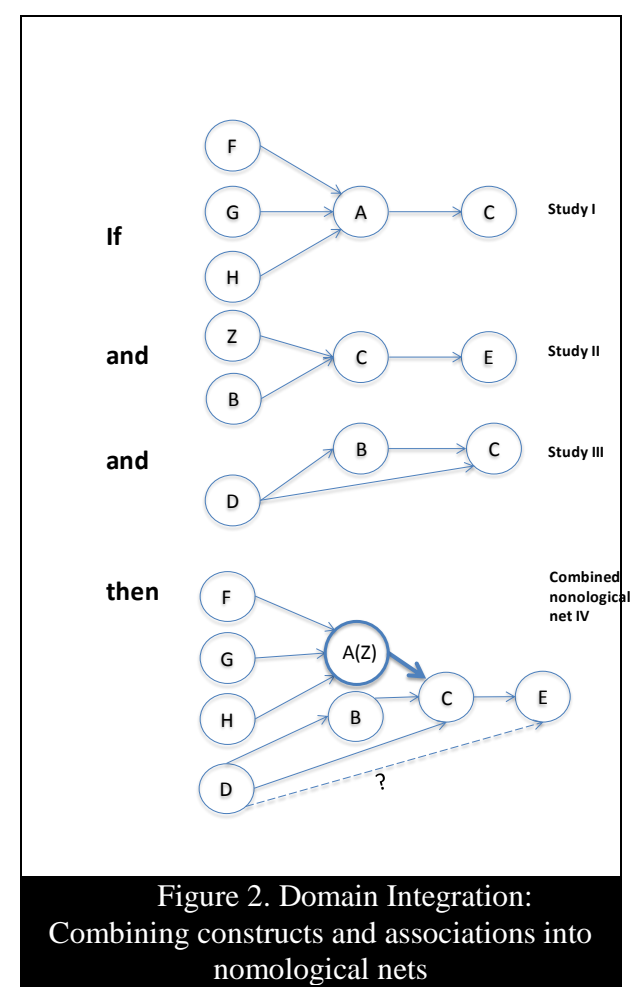

The combination of associations between constructs-in-common also reveals that construct $\mathrm{C}$ mediates the association of $\mathrm{B}$ and $\mathrm{E}$. The inclusion of additional studies will reveal multiple synonymous constructs and corroborated associations revealing densities of theory importance and corroboration of associations. The network will obtain novelty as some of the associations will be new and potentially unstudied. For example, the combined network suggests the possibility of a direct $\mathrm{D}-\mathrm{E}$ association (dotted line). One implication of Weber's framework is that theory development need not correspond to reality ex ante. Thus we can articulate propositions that clearly define the state space and boundary events covered by specific theoretical elements within our nomological network. With the potential of the entire set of quantitative IS research as data, we problematize the extant research by shaping larger or smaller areas of underdeveloped or unrecognized investigative areas [34] within the set of established corroborated data. This approach focuses 
attention on the overall structure of the external nomological network in which theories are embedded rather than internal elements which make up individual theories. In theory development, this provides a balance between internal coherence at the smaller grain-size of associations and external coherence at the coarser grain-size of the underlying nomological structure.

By locating situated individual theories in a field of external coherence, we posit that every theory is embedded in a larger network of constructs by nomological associations - a nomological network, which itself represents multiple interwoven research programs in the IS discipline. This conception of a broad nomological network underlies Cronbach and Meehl's [35] influential concept of construct validity, Benbasat and Zmud's [36] argument for an IS core identity as well as research on IS theorizing [37]. External coherence also permits the visualization of the number of corroborations of specific associations and the mapping of densities of highly studied models as a measure of theory importance. This mapping will also reveal where associations among constructs have been underdeveloped or underspecified.

\subsection{Mode 3: Inter-field Theory Integration}

Multiple academic fields, including Management, Accounting, Psychology, Behavioral Medicine, Organizational Behavior and others overlap in the same domain space of inquiry as Information Systems. Indeed IS has long been accused of being overly reliant on importing theories from reference disciplines [for a discussion see: 38 ].

One approach to integration across field domains was suggested by Koch et. al. [3] to justify combining evolutionary theory and nonevolutionary IS theoretical perspectives. In identifying an approach to theory integration they argued that there are four important preconditions: (1) similarity of dependent variables between theories; (2) technology similarity between theories; (3) similar theoretical constructs; and (4) complementarity. These guidelines are potentially useful when fields are discussing similar tasks using similar technology and similar constructs.

We propose a different approach to Interfield Integration where "two fields share an interest in explaining different aspects of the same phenomenon and when background knowledge already exists relating the two fields"
[39 abstract]. Here, rather than borrowing or adapting theory, the focus is on identifying where the approaches in two disciplines make visible complementary qualities of the phenomenon and neither field is equipped to advance theory on its own.

An example of this approach from biochemistry [39] illustrates specific differences from the previous instance of combining evolutionary and non-evolutionary theory. Darden and Maul's analysis identifies four justifications for theory integration (Fig 3):

(1) Field A may specify a physical location of a construct or entity postulated in Field B. In their example the chromosome theory proposed that genes located on chromosomes which the field of cytology provided the physical location of the genes. Further research clarified the partwhole relationship of genes to chromosomes.

(2) Field A may identify the physical characteristics or properties of a construct or entity that Field B postulates. For examples chemical repressors were characterized by biochemistry after such repressors were postulated in genetics theory.

(3) Field A may determine structures of entities whose functions are the domain of other fields. For example molecular structures are a focus for physical chemistry but molecular functions are the domain of biochemistry.

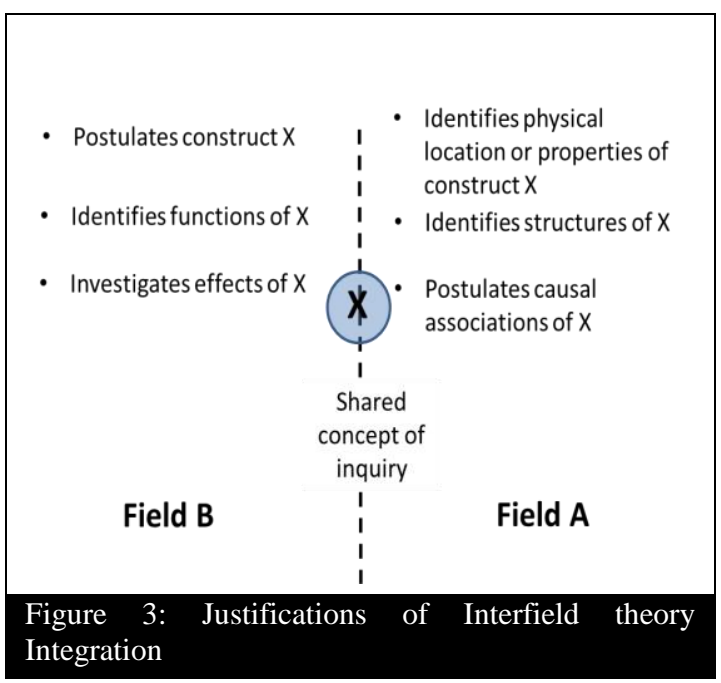

(4) Finally, causal relationships may exist in two fields such that constructs or entities postulated in one field have causal significance effects investigated in other fields. For example, "the theory of [allosteric] regulation provides a 
causal explanation of the interaction between the physicochemical structure of certain enzymes and a characteristic biochemical pattern of their activity" [39 p. 48].

These guidelines carry the concept we build up theories by introducing "new theoretical entities and postulate new processes which were not contemplated in either theory taken alone" [40 p. 266]. We add to this set of guidelines that Inter-field Integration is warranted where one field conceptualizes distinct entities that do not exist in the other field. While the example provided above of this type of 'building up' is from vitamin research and medical studies [40], we find analogies in IS studies. In one instance Gibson's perceptual affordances disclose a reconceptualization of technology "use" [41] as a fusion. In a second instance IS development is conceptualized as a complex evolutionary process [42] rather than a linear or phased implementation. In the former, affordance, from ecological psychology and studies of perception conceptualizes the fusion of mobile technology into activities in a way that changes the person's perception of the world. In the latter, system development is viewed through the perspective of evolutionary theory to conceptualize a complex process of give-and -take among competing but co-constituting assembledges.

\section{Discussion}

In providing a framework (Fig 4) for the rigorous integration of theories within and across discipline boundaries we shift the focus from constructing novel theories to providing a conceptual apparatus for understanding similarities and differences among existing theories which might not have been noticed. The potential is to build upon existing knowledge, established constructs, associations and concepts to build more robust theories with a broader scope. While narrow theories have a rightful role, the IS field is not yet taking advantage of accumulate knowledge in a systematic manner. Our focus on integration provides three contributions to IS:

First, initial results from two approaches to construct extraction and visualization for theory development [24, 43] demonstrates the potential to vitalize theory development among the business sciences and interfield theory development across disciplinary boundaries. The reduction of synonymous constructs and the integration of multiple theories/models which account for the same phenomenon will bring much needed clarity to Information Systems by reducing construct and theory clutter.

Second, a focus on integration of empirically corroborated associations among constructs (rather than just propositions) will require researchers to attend to construct-construct associations in the literature in a more rigorous manner. Not only is the collection of such information more complex, but it also requires much stronger researcher skills in statistics. A project that has been successful in approaching this is MetaBus which aims to automate metaanalyses [44]. While enabling hypothesis generation and the development of more robust theories this approach to integration requires attention to the means by which theories resulting from integration can be tested and validated.

\begin{tabular}{|c|c|c|c|}
\hline & $\begin{array}{l}\text { Semantic } \\
\text { Similarity }\end{array}$ & $\begin{array}{l}\text { Nomological } \\
\text { Coherence }\end{array}$ & $\begin{array}{l}\text { Part-Whole } \\
\text { corresponden } \\
\text { ce }\end{array}$ \\
\hline$\frac{\pi}{8}$ & $\begin{array}{l}\text { Detection of } \\
\text { semantically } \\
\text { synonymous } \\
\text { constructs. } \\
\text { Validate use } \\
\text { of core } \\
\text { constructs }\end{array}$ & $\begin{array}{l}\text { Examination } \\
\text { of context and } \\
\text { setting } \\
\text { through } \\
\text { nomological } \\
\text { network } \\
\text { similarity. }\end{array}$ & \\
\hline$\frac{N}{2}$ & $\begin{array}{l}\text { Examination } \\
\text { of similarities } \\
\text { to determine } \\
\text { coherence } \\
\text { between } \\
\text { disparate } \\
\text { theories. }\end{array}$ & $\begin{array}{l}\text { Examination } \\
\text { of theoretical } \\
\text { coherence } \\
\text { through } \\
\text { nomological } \\
\text { network (high } \\
\text { correlations). }\end{array}$ & $\begin{array}{l}\text { Detection of } \\
\text { whole-part } \\
\text { relationships } \\
\text { through mid- } \\
\text { range } \\
\text { correlations in } \\
\mathrm{NN} \text {. }\end{array}$ \\
\hline en & $\begin{array}{l}\text { Detection of } \\
\text { semantically } \\
\text { synonymous } \\
\text { constructs in } \\
\text { separate } \\
\text { fields. }\end{array}$ & & $\begin{array}{l}\text { 'Build up' } \\
\text { part/whole } \\
\text { theories from } \\
\text { structures, } \\
\text { functions, } \\
\text { locations and } \\
\text { causal } \\
\text { linkages. }\end{array}$ \\
\hline
\end{tabular}

Finally, our framework provides a conceptual apparatus that calls attention to the potential for unrecognized semantic similarities, for nomological associations, and for part-whole relations which reductionist approaches obscure. This opens up for future use of ontologies and ontology learning. Such ontologies would provide an organizing map of constructs and classes of phenomenon in IS, aid meta-theoretic research, and organize IS research to be more 
accessible for practice. The contribution of theory ontologies in the domain of Behavioral Medicine include the establishment of a shared vocabulary for classes of phenomenon and the specification of relationships between classes [45]. This framework may enable more considered approaches to theory integration that will strengthen a cumulative tradition of theory development in IS and enable research to be shared more coherently across the field and among related fields.

\section{References}

[1] Avison, D., and Malaurent, J., "Is Theory King?: Questioning the Theory Fetish in Information Systems", Journal of Information Technology, 29(4), 2014, pp. 327-336.

[2] Straub, D.W., "Editor's Comments: Why Top Journals Accept Your Paper", MIS Quarterly, 33(3), 2009, pp. iii-ix.

[3] Koch, N., "Information Systems Theorizing Based on Evolutionary Psychology: An Interdisciplinary Review and Theory Integration Framework", MIS Quarterly, 33(2), 2009, pp. 395-418.

[4] Steel, P., and König, C.J., "Integrating Theories of Motivation", Academy of Management Review, 31(4), 2006, pp. 889-913.

[5] Wilson, E.O., Consilience: The Unity of Knowledge, Vintage, 1999.

[6] Grudin, J., "Theory Weary", IACM Interactions, 2014

[7] Weber, R., "Evaluating and Developing Theories in the Information Systems Discipline", JAIS, 13(1), 2012, pp. 1-30.

[8] Kuhn, T.S., The Essential Tension, Chicago Press, Chicago, 1977.

[9] Murphy, P., "Coherentism in Epistemology. Internet Encyclopedia of Philosophy", Internet Encyclopedia of Philosophy, 2006

[10] Larsen, K., and Bong, C.H., "A Tool for Addressing Construct Identity in Literature Reviews and Meta-Analyses", MISQ, 2016 (forthcoming)

[11] Davis, F.D., "Perceived Usefulness, Perceived Ease of Use, and User Acceptance of Information Technology", MIS Quarterly, 1989, pp. 319-340.

[12] Venkatesh, V., Morris, M.G., Davis, G.B., and Davis, F.D., "User Acceptance of Information Technology: Toward a Unified View", MIS Quarterly, 27(3), 2003, pp. 425-478. [13] Kim, S.S., "The Integrative Framework of Technology Use: An Extension and Test", MIS Quarterly, 2009, pp. 513-537.
[14] Thompson, R.L., Higgins, C.A., and Howell, J.M., "Influence of Experience on Personal Computer Utilization: Testing a Conceptual Model", Journal of Management Information Systems, 11(1), 1994, pp. 167-187.

[15] Taylor, S., and Todd, P.A., "Understanding Information Technology Usage: A Test of Competing Models", Information Systems Research, 6(2), 1995, pp. 144-176.

[16] Igbaria, M., Parasuraman, S., and Baroudi, J.J., "A Motivational Model of Microcomputer Usage", Journal of Management Information Systems, 13(1), 1996, pp. 127-143.

[17] Kim, H.-W., and Kankanhalli, A., "Investigating User Resistance to Information Systems Implementation: A Status Quo Bias Perspective", MIS Quarterly, 2009, pp. 567-582.

[18] Brown, S.A., and Venkatesh, V., "Model of Adoption of Technology in Households: A Baseline Model Test and Extension Incorporating Household Life Cycle", MIS Quarterly, 2005, pp. 399-426.

[19] Larsen, K., and Bong, C.H., "A Tool for Addressing Construct Identity in Literature Reviews and Metaanalyses", MIS Quarterly, 40(3) 2016 pp. 529-551

[20] Hovorka, D.S., Birt, J., Larsen, K.R., and Finnie, G., "Visualizing the Core-Periphery Distinction in Theory Domains", ACIS, 2012, pp. 1-10.

[21] Larsen, K., Monarchi, D., Hovorka, D., and Bailey, C., "Analyzing Unstructured Text Data: Using Latent Categorization to Identify Intellectual Communities in Information Systems", Decision Support Systems, 45(4), 2008, pp. 884-896.

[22] Kuhn, T.S., The Structure of Scientific Revolutions, University of Chicago Press, 3rd edn, Chicago, IL, 1962.

[23] Kuhn, T., The Road since Structure, University of Chicago Press, Chicago, 2000.

[24] Li, J., and Larsen, K., "Establishing Nomological Networks for Behavioral Science:

A Natural Language Processing Based Approach", International Conference on Information Systems, Shanghai, 2011

[25] Bacharach, S.B., "Organizational Theories: Some Criteria for Evaluation", Academy of Management Review, 14(4), 1989, pp. 496-515.

[26] Kaplan, A., The Conduct of Inquiry: Methodology for Behavirol Science, Chandler Publishing Company, 1964.

[27] Mayer, K.J., and Sparrowe, R.T., "Integrating Theories in Amj Articles", Academy of Management Journal, 56(4), 2013, pp. 917922. 
[28] Burton-Jones, A., and Gallivan, M., "Towards a Deeper Understanding of System Usage in Organizations: A Multilevel Perspective", MISQ, 31(4), 2007, pp. 657-679.

[29] Geels, F.W., "Technological Transitions as Evolutionary Reconfiguration Processes: A Multi-Level Perspective and a Case-Study", Research Policy, 31( ), 2002, pp. 1257-1274.

[30] Hovorka, D.S., Larsen, K., Birt, J., and Finnie, G., "A Meta-Theoretic Approach to Theory Integration in Information Systems", in 46th Hawaii International Conference on System Sciences 2013

[31] Larsen, K., Voronovich, Z., Cook, P., and Pedro, L., "Addicted to Constructs: Science in Reverse?", Addiction, Article first published online: 30 MAY (2013,

[32] Weinstein, N., and Rothman, A., "Commentary: Revitalizing Research on Health Behavior Theories", Health Education Research: Theory \& Practice, 20(3), 2005, pp. 294-297.

[33] Thornberry, T.P., "Reflections on the Advantages and Disadvantages of Theoretical Integration", Theoretical integration in the study of deviance and crime: Problems and prospects, 1989, pp. 51-60.

[34] Locke, K., and Golden-Biddle, K., "Constructing Opportunities for Contribution: Structuring Intertexual Coherence and "Problematizing" in Organizational Studies", Academy of Management Journal, 40(5), 1997, pp. 1023-1062.

[35] Cronbach, L., and Meehl, P., "Construct Validity in Psychological Tests", Psychological Bulletin 52(1955, pp. 281-302.

[36] Benbasat, I., and Zmud, R.W., "The Identity Crisis within the Is Discipline: Defining and Communicating the Discipline's Core Properties", Information Systems Research, 27(2), 2003, pp. 183-194.

[37] Furneaux, B., and Wade, M., "Theoretical Constructs and Relationships in Information Systems Research", in (Dwivedi, Y., Lal, B.,
Williams, M.D., Schneber, S.L., and Wade, M., 'eds.'): Handbook of Research on Contemporary Theoretical Models in Information Systems, IGI Global, 2009

[38] Baskerville, R., and Myers, M., "Information Systems as a Reference Discipline", MIS Quarterly, 26(1), 2002, pp. 114.

[39] Darden, L., and Maull, N., "Interfield Theories", Philosophy of science, 44(1977, pp. 43-64.

[40] Bectel, W., "The Nature of Scientific Integration", Kluwer Academic Publishers., Dordretcht, 1986

[41] Hafermalz, E., Hovorka, D., and Riemer, K., "Shared Secret Places: Social Media and Affordances", arXiv preprint arXiv:1606.02478, 2016,

[42] Montealegre, R., Hovorka, D.S., and Germonprez, M., "A Coevolutionary View of Information Services Development: Lessons from the Us National Oceanic and Atmospheric Administration", Journal of the Association for Information Systems, 15(9), 2014, pp. 577.

[43] Larsen, K., and Hovorka, D.S., "Developing Interfield Nomological Nets", Hawaii International Conference on System Science, Maui, 2012

[44] Bosco, F.A., Steel, P., Oswald, F.L., Uggerslev, K., and Field, J.G., "Cloud-Based Meta-Analysis to Bridge Science and Practice: Welcome to Metabus", Personnel Assessment and Decisions, 1(1), 2015,

[45] Larsen, K.R., Michie, S., Hekler, E.B., Gibson, B., Spruijt-Metz, D., Ahern, D., ColeLewis, H., Ellis, R.J.B., Hesse, B., and Moser, R.P., "Behavior Change Interventions: The Potential of Ontologies for Advancing Science and Practice", Journal of Behavioral Medicine, 2016, pp. 1-17. 